\title{
Correlation of Hormonal Receptors Estrogen Receptor, Progesterone Receptor and Her-2/Neu with Tumor Characteristics in Breast Carcinoma: Study of 100 Consecutive Cases
}

\author{
Priyadarshini Biswal, Susmita Behera, Asaranti Kar, Dilleswari Pradhan, \\ Pradeep Kumar Behera, Subrat Burma, Chandraprava Mishra
}

Department of Pathology, S.C.B. Medical College, Cuttack, India

Email: asarantikar@yahoo.co.in

Received 6 July 2015; accepted 26 December 2015; published 29 December 2015

Copyright (C) 2015 by authors and Scientific Research Publishing Inc.

This work is licensed under the Creative Commons Attribution International License (CC BY). http://creativecommons.org/licenses/by/4.0/

(c) (i) Open Access

\begin{abstract}
Introduction-Breast cancer is the most common cancer and leading cause of death in women. In India, its incidence is rapidly rising over last few decades. Present study is aimed to study the pattern of expression of hormonal receptors and Her-2/neu in invasive breast carcinoma and to correlate estrogen receptor (ER), progesterone receptor (PR) and Her-2/neu expressions with various clinicopathological parameters. Material and methods: The present study was carried out in Department of Pathology, S.C.B. Medical College, Cuttack in the year 2013 taking consecutive 100 cases. Routine H\&E staining for histological diagnosis and IHC analysis for ER, PR and Her 2/ neu was carried out in all 100 cases of breast malignancies. Results: $99 \%$ of cases are invasive breast carcinoma, not otherwise specify (IDC-NOS). The age ranges from 23 years to 72 years. Majority of tumors are of grade $2(\mathbf{7 0 \%})$ followed by grade $3(30 \%)$. ER PR and Her-2/neu expression are seen in $45 \%, 35 \%$ and $30 \%$ respectively. Triple negative cases comprise $35 \%$. Higher number of grade 2 tumor shows ER, PR positivity as compared to grade 3 tumors. Her-2/neu expression does not show any significant correlation with age or lymph node status of the patient. Conclusion: ER and PR expression in breast cancers in the current study are found to be comparable to the findings of other authors, but the frequency of HER-2/neu expression is slightly higher. Significant correlation is observed between hormonal receptor status and the grade of the tumor. Inverse relationship is found between Her-2/neu expression and ER, PR receptor status. Her-2/neu expression is increased with size and high grade of tumor.
\end{abstract}




\section{Keywords}

\section{Breast Carcinoma, Estrogen Receptor (ER), Progesterone Receptor (PR), Her-2/Neu, Immunohistochemistry}

\section{Introduction}

Breast cancer is the most common cancer of women in developed countries and $12 \%$ breast cancers occur between 20 - 34 years [1]. In India, breast cancer is second to cancer of the cervix among women, but is considered the leading cancer in certain metros such as Mumbai and Bangalore. It is estimated that approximately 80,000 cases occur annually. Breast cancer is strongly related to age, with only 5\% of all breast cancers occurring in women under 40 years old [2]. Several pathological features have prognostic significance in breast carcinoma which includes histologic subtypes, grade, lymph node status, estrogen receptor (ER)/progesterone receptor (PR) status, growth factor and its receptors, proliferation activity and DNA content with tumor suppressor genes and oncogenes [3]. Prognosis of breast carcinoma is worse with higher grade, tumor subtypes like medullary and lobular carcinoma, lymph node metastasis, negativity for ER, PR and positivity for Her-e/neu, with excess of oncogenes and also presence of BRCA gene. Out of these, ER, PR and Her-2/neu immunostaining are a very useful tool for rapid diagnosis, treatment and prognosis of the patient. Determination of ER, PR status on biopsy specimens prior to therapeutic intervention is advocated as a standard practice [4]. Due to this, breast cancer is better represented by its combined receptor expression than by a single receptor status alone. Recent management protocol is focusing on separating triple negative and triple positive tumors for treatment and prognosis. With this background, the present study is undertaken to analyze the pattern of expression of hormone receptor ER, PR and Her-2/neu in invasive breast carcinoma and to correlate them with various clinicopathological parameters, especially in this part of country where studies are limited.

\section{Materials and Methods}

This study was carried out in the year 2013 taking 100 consecutive cases. The study was done as per standard ethics. All the cases histopathologically diagnosed as invasive carcinoma were included in the study. The clinical details like age, sex, duration of symptoms, laterality, size of the tumor, axillary lymph node status and imaging findings like MRI were recorded in each case. After carrying out the detailed gross examination, all tissues were fixed in 10\% buffered formalin. Multiple sections were taken from the tumor and its margins and all the lymph nodes. Histopathological study of the specimen was done by Haematoxylin and Eosin staining and as per standard protocol. Grading of the tumor was done by modified Bloom Richardson grading system. Immunohistochemistry (IHC) for ER, PR and Her-2/neu was performed on representative blocks of paraffin embedded tissue in each case. 3 - 4 micron thick sections were submitted for IHC staining. Antigen retrieval was done by HIER method using citrate buffer at ph 2.5 for ER/PR and ph 6 for Her-2/neu. The normal epithelial component present in the tissue section served as internal control for ER/PR. IDC-NOS with known Her-2/neu over expression was used as external positive control for Her-2/neu with each lot of staining. The ER+ve cells showed nuclear staining (Figure 1) where the percentage of positive cells were counted and the intensity of staining was

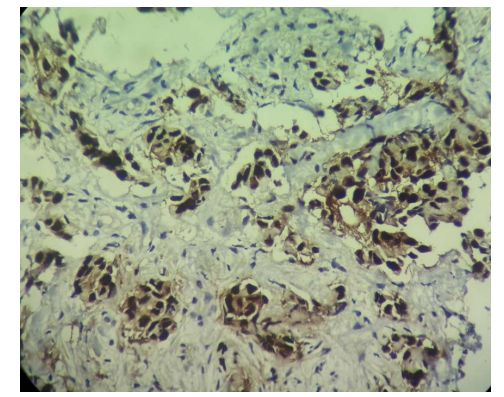

Figure 1. Photomicrograph showing ER positivity of malignant tumor cells of IDC-NOS of breast. IHC $\times 400$. 
recorded. For PR also nuclear staining was observed (Figure 2) and accrodingly scored. Her-2/neu is a membrane stain and Her-2/neu positive cells showed intense membrane staining (Figure 3) without cytoplasmic staining.

Following scoring system was used for noting down the results of immunohistochemistry in each case.

\section{Interpretation of IHC in Carcinoma Breast}

All red score for ER and PR Evaluation in Ca Breast.

\begin{tabular}{cccc}
\hline Proportional score (PS) & Percentage of positive cells & Intensity score & Intensity of positivity \\
\hline 0 & 0 & 0 & None \\
1 & $<1$ & 1 & Weak \\
2 & $1-10$ & 2 & Sntermediate \\
3 & $11-33$ & 3 & Strong \\
4 & $34-66$ & Interpretation \\
\hline & & Negative \\
\hline & & Positive \\
\hline
\end{tabular}

Interpretation of Her-2/Neu by IHC.

\begin{tabular}{cc}
\hline IHC score & Criteria \\
\hline 0 (Negative) & No reactivity/Reactivity in $\leq 10 \%$ tumour cells \\
$1+$ (Negative) & Faint weak reactivity in $>10 \%$ of tumour cells but only a portion of the membrane is positive \\
$2+$ (Equivocal) & $\begin{array}{l}\text { Weak to moderate complete membrane reactivity in }>10 \% \text { of tumour } \\
\text { cells or circumferential intense membrane staining in } \leq 30 \% \text { of cells }\end{array}$ \\
$3+$ (Positive) & $\begin{array}{c}\text { of tumour cell must show circumferential intense and uniform membrane } \\
\text { staining. A homogenous (Chicken wire) pattern should be present }\end{array}$ \\
\hline
\end{tabular}

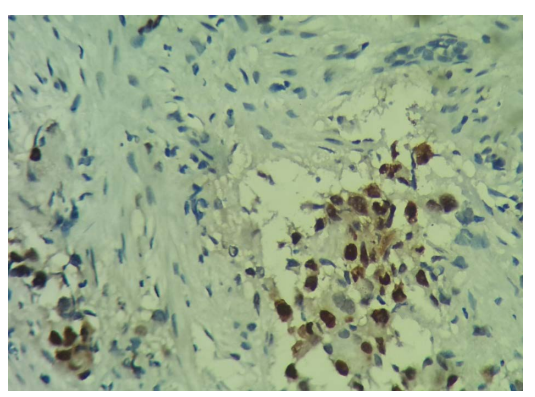

Figure 2. Photomicrograph showing PR positivity of nuclei malignant tumor cells of IDC-NOS of breast. IHC $\times 200$.

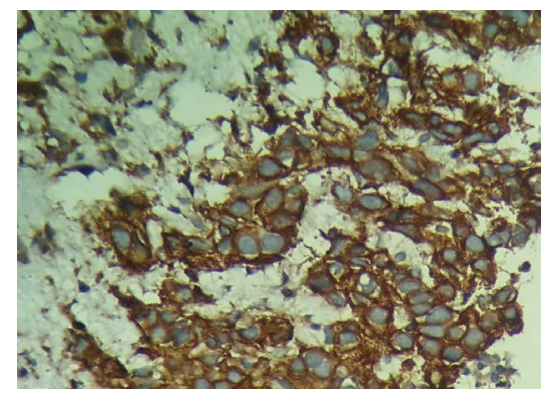

Figure 3. Photomicrograph showing Her-2/neu positivity of cytoplasmic membrane of malignant tumor cells of IDC-NOS of breast. IHC $\times 400$. 


\section{Results}

In our study, a total of 100 consecutive cases of invasive carcinoma of breast were taken. Age of the patients ranged from 23 - 73 years. Most common age group was 41 - 50 (37\% cases) as shown in Table 1. Majority of the patients were above 40 years of age.

All cases except one were IDC-NOS and only one case was diagnosed as medullary carcinoma. Majority (70 cases $-70 \%$ ) belonged to grade 2 according to B-R Grading system. However, lymph nodes were negative in maximum cases i.e. 73 negative in comparison to 27 positive cases (Table 2). ER and PR were positive in $45 \%$ and $35 \%$ cases respectively. Her-2/neu was found to be negative in 70 cases (70\%).

Correlation of ER, PR and Her-2/neu with grade of tumor has been shown in Table 3. Grade 2 tumors showed maximum ER positivity (40 cases or $40 \%$ ) and minimum Her-2/neu positivity.

Table 1. Age distribution of patients of invasive ductal carcinoma-NOS of breast.

\begin{tabular}{ccc}
\hline Age group & Cases & Percentage (\%) \\
\hline $21-30$ & 05 & 05 \\
$31-40$ & 23 & 23 \\
$41-50$ & 37 & 24 \\
$51-60$ & 24 & 09 \\
$61-70$ & 09 & 02 \\
$71-80$ & 02 & \\
Total & 100 & 24 \\
\hline
\end{tabular}

Table 2. Comparative analysis of clinicopathological features and receptor status of breast carcinoma.

\begin{tabular}{|c|c|c|c|}
\hline Histopathological features & & Number & Percentage \\
\hline \multirow[t]{2}{*}{ Type } & IDC NOS & 99 & 99 \\
\hline & Medullary carcinoma & 01 & 01 \\
\hline \multirow[t]{3}{*}{ Grade } & 1 & Nil & \\
\hline & 2 & 70 & 70 \\
\hline & 3 & 30 & 30 \\
\hline \multicolumn{4}{|l|}{ Tumour size } \\
\hline & Less than $2 \mathrm{~cm}$ & 14 & 14 \\
\hline & More than $2 \mathrm{~cm}$ & 86 & 86 \\
\hline \multirow[t]{2}{*}{ Lymph node status } & Positive & 27 & 27 \\
\hline & Negative & 73 & 73 \\
\hline \multirow[t]{2}{*}{ ER } & Positive & 45 & 45 \\
\hline & Negative & 55 & 55 \\
\hline \multirow[t]{2}{*}{ PR } & Positive & 35 & 35 \\
\hline & Negative & 65 & 65 \\
\hline \multirow[t]{2}{*}{ Her2/neu } & Positive & 30 & 30 \\
\hline & Negative & 70 & 70 \\
\hline
\end{tabular}

Table 3. Comparison of ER, PR, Her2/neu IHC positivity with grade of breast carcinoma.

\begin{tabular}{cccccc}
\hline Grade & Cases & ER positivity & PR positivity & Her2/neu positivity \\
\hline 2 & 70 & 40 & 28 & 06 \\
3 & 30 & 05 & 07 & 24 \\
\hline
\end{tabular}

Triple positive—Grade 2 - 18 cases (18\%), Grade 3 - 12 cases (12\%); Triple negative—Grade 2 - 20 cases (20\%), Grade 3 - 15 cases (15\%). 


\section{Discussion}

Present study comprised of 100 cases of primary breast carcinoma. Majority of cases were seen in between 4th to 6th decades, mostly perimenopausal and postmenopausal females. $86 \%$ of the cases (Table 2) showed more than $2 \mathrm{~cm}$ tumor size. This was compatible to the results observed in Eastern countries like Aziun Nisa et al, A Moses et al. and Mona M Rashed et al. [5]-[7]. Studies from Western country, Adendaya et al. showed 71\% cases with less than $2 \mathrm{~cm}$ size which could be due to early cancer detection programme [8]. Present study showed $45 \%$ of cases with positive ER status while 35\% PR positive status. Simultaneous triple negative breast cancer was found in 35\% (35 cases) and simultaneous triple positive breast cancer occurred in 30\% (30 cases). The study by Mona A Rashed et al. showed $41.41 \%$ positivity for ER and PR. The original work done by Sheet $\mathrm{T}$ et al. also revealed similar result [9]. Azizun Nisa et al. showed 32.7\% \& $25.3 \%$ ER and PR positivity respectively. But the incidence of both triple negative and triple positive cases were more in present study. Significant inverse association was found between hormonal receptor and histology grade (Table 2). Greater percentage of grade 2 tumors had ER, PR positivity as compared to grade 3 tumors (Table 3). Findings observed by Azizun Nisa et al., showed similar results. Her-2/neu positivity in our study was $30 \%$. Earlier studies detected $17.7 \%$ to $27.58 \%$ positivity by different authors.

In our study, Her-2/neu receptor revealed a significant inverse association with hormonal receptor status. We found that ER, PR expression was increased in Her-2/neu negative tumors as compared to Her-2/neu positive tumors. Similar results were found by Mona M Rashed et al. Triple negative breast carcinoma is characterized by lack of ER, PR and Her-2/neu expression. Our study showed 35\% cases as triple negative. Study by Bhagat Vasudha $\mathrm{M}$ et al. showed $25.86 \%$ cases and Patil et al. showed $19.9 \%$ cases as triple negative respectively.

Triple negativity was again found in $20 \%$ of breast carcinomas with a histopathologic grade 2 cases where as it was slightly reduced i.e. $15 \%$ in grade 3 breast carcinomas. Similarly triple positivity was seen in $18 \%$ of grade 2 tumours and about $12 \%$ in grade 3 tumours.

In our institutions IDC-NOS was diagnosed in almost all cases of breast carcinomas (99\%). Only 1 case of medullary carcinoma of breast was encountered among the total cases studied. Comparing the statistics of western countries, our studies show that we had infiltrating ductal carcinoma NOS as the most common breast cancer [8]. Most of the patients were detected in stage 2 or stage 3 as compared to western studies where the patients are detected in stage 1 also. So early detection programmes need to be more strengthened in developing countries like India.

\section{Conclusion}

In present study, ER, PR and Her-2/neu expression in breast carcinoma by IHC method indicate higher rate of positive expression correlated with various clinicopathological aspects. Higher number of grade 2 tumor shows ER, PR positivity as compared to grade 3 tumors. Inverse relationship is observed between Her-2/neu expression and ER, PR receptor status. Her-2/neu expression is increased with increased grade of the tumor. ER, PR and Her-2/neu do not show any significant correlation with lymph node status and age.

\section{References}

[1] Mir, R. and Singh, V.P. (2009) Breast Cancer in Young Women and Its Impact on Reproductive Function. Apollo Medicine, 6, 200-208. http://dx.doi.org/10.1016/S0976-0016(11)60528-0

[2] (2009) Breast Cancer: Breast Cancer in Young Women. WebMD.

[3] Naeem, M., Nasir, A., Aman, Z., Ahmad, T. and Samad, A. (2008) Frequency of Her 2/Neu Positivity and Its Association with Other Features of Breast Cancer. J Ayub Med Coll, 20, 23-26.

[4] Munjal, K., Ambaye, A., Vans, M.F.E., et al. (2009) IHC Analysis of ER, PR and Her 2 Neu in Infiltrative Breast Carcinoma. Asian Pacific Journal of Cancer Prevention, 10, 773-778.

[5] Azizun-Nisa et al. (2008) Comparision of ER, PR \& Her 2 Neu Status in Breast Cancer. Asian Pacific Journal of Cancer Prevention, 9, 553-556.

[6] Moses, A., Ghosh, M., et al. (2011) IHC Profile of Breast Cancer Patients at a Tertiary Care Hospital in South India. Asia Pacific Journal of cancer Prevention, 12, 625-629.

[7] Rashed, M.M., et al. (2007) The Association of Her 2 Neu over Expression in Relation to p53 Neuclear Accumulation, Hormonal Receptor Status \& Clinic-Pathological Correlation in a Series of Egyptian Women with Invasive Ductal 
Carcinoma. European Journal of General Medicine, 4, 73-79.

[8] Antalio, A.A. and Eugler, J.M. (2009) Breast Cancer Subtype Based on ER/PR and Her 2 Neu Expression. Clinical Medicine Research, 7, 4-13.

[9] Sheet, T., Atin, A., et al. (2009) Hormone Receptor Status over last 8 Years in a Cancer Referral Centre in India; What Was and It Is. Indian Journal of Pathology and Microbiology, 52, 171-174. http://dx.doi.org/10.4103/0377-4929.48909 